\title{
Salt-losing syndrome in 2 infants with defective 18-dehydrogenation in aldosterone biosynthesis
}

\author{
P. J. MILLA, R. TROMPETER, M. J. DILLON, D. ROBINS, ${ }^{*}$ AND C. SHACKLETON $\dagger$ \\ From The Hospital for Sick Children and Institute of Child Health, London
}

SUMmaRY Two infants presented with a salt-losing syndrome, the presenting features of which were subtle. One case appeared to be transient. Deficient production of aldosterone was shown by plasma renin activity and plasma aldosterone profile. Gas chromatography-mass spectrometry of urine indicated a defect in 18-dehydrogenation of 18-hydroxycorticosterone. Treatment with salt supplements and $9 \alpha$-fludrocortisone reversed the salt-losing state and in one case treatment was later stopped. Although the disease may appear transient, the biochemical defect is persistent and for adequate growth a positive salt-balance is necessary.

Salt loss of adrenal origin is due to defective production of aldosterone. This may be associated with deficient production of other adrenal steroids or can be an isolated defect of 18-oxidation of corticosterone. This study concerns 2 children with hypoaldosteronism due to defective 18-dehydrogenation of 18-hydroxycorticosterone. The presenting features of failure to thrive, anorexia, vomiting, loose stools, and intermittent pyrexia were subtle. Abnormalities of the serum electrolytes were transient. Plasma renin activity (PRA) and aldosterone concentration (PAldo) profiles showed an inappropriate secretion of aldosterone at a time of salt loss. These findings were helpful in making an early diagnosis in one child and confirming a suspected diagnosis in the other.

\section{Case reports}

Case 1. A male infant was born at term, birthweight $2 \cdot 8 \mathrm{~kg}$. There were 2 healthy male sibs. He was fed with a cows' milk formula, and remained well until the end of the first week of life. He then began to vomit his feeds. A urinary tract infection was diagnosed and the symptoms resolved with antibiotic treatment. Throughout the following months he fed poorly and vomited frequently. Growth retardation was prominent in spite of the introduction of solids.

Received 9 December 1976

Present addresses:

*Children's Hospital, Ladywood Middleway, Birmingham B16 8ET

tClinical Research Centre, Northwick Park Hospital, Harrow, Middlesex
He was investigated at the age of 8 months. He was then a small infant of $5.3 \mathrm{~kg}$ and height $63 \mathrm{~cm}$. There was no abnormal pigmentation. Blood pressure $80 / 50 \mathrm{mmHg}$. The male external genitalia were normal.

Initial investigations showed a normal blood count and plasma electrolytes; blood urea 8.5 $\mathrm{mmol} / 1(51 \mathrm{mg} / 100 \mathrm{ml})$. Urine was sterile and an intravenous pyelogram normal. Shortly after admission he became dehydrated after a minor episode of diarrhoea and vomiting. At this time, plasma $\mathrm{Na}$ was $<122 \mathrm{mmol} / 1$ ( $<122 \mathrm{mEq} / \mathrm{l}), \mathrm{K} 6 \cdot 6$ $\mathrm{mmol} / \mathrm{l}(6.6 \mathrm{mEq} / \mathrm{l})$, and blood urea $15.1 \mathrm{mmol} / \mathrm{l}$ $(91 \mathrm{mg} / 100 \mathrm{ml})$. Urinary $\mathrm{Na}$ excretion was $36 \mathrm{mmol} /$ $24 \mathrm{~h}$, and $\mathrm{K} 8 \mathrm{mmol} / 24 \mathrm{~h}$ when $\mathrm{Na}$ intake was $77 \mathrm{mmol} / 24 \mathrm{~h}$. During the initial salt-wasting period inappropriately low levels of PAldo were found compared with extremely high PRA. These investigations together with others of adrenal function are summarized in Table 1. Serial 24-hour urine collections during the salt-wasting period were assayed for excretion of aldosterone metabolites and precursors (Table 2).

$\mathrm{Na}$ balance and clinical progress are shown in Fig. 1. Several episodes of pyrexia, vomiting, and loose stools occurred for which no infective cause could be found. During these episodes excessive urinary salt loss occurred. Initial management consisted of increasing salt intake to correct excessive salt loss until preliminary investigations were complete. PRA/PAldo profiles strongly suggested a deficient aldosterone secretion, and replacement therapy was started with $9 \alpha$-fludrocortisone $(9 \alpha \mathrm{FC})$, $0.05 \mathrm{mg} /$ day. In spite of this, further episodes of salt- 
Table 1 18-dehydrogenase defect

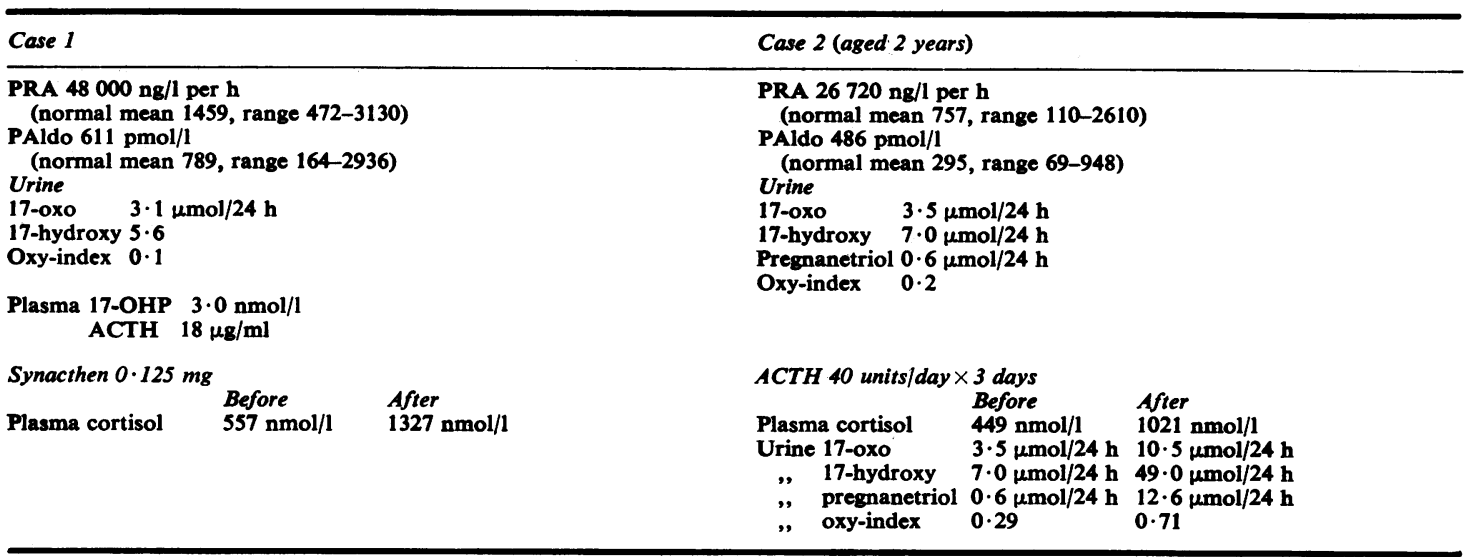

PRA $=$ plasma renin activity; PAldo $=$ plasma aldosterone.

Table 2 Urinary excretion of aldosterone precursors and metabolites with plasma electrolyte and treatment data

\begin{tabular}{|c|c|c|c|c|c|}
\hline & \multicolumn{4}{|l|}{ Case 1} & \multirow{2}{*}{$\frac{\text { Case } 2}{16 \text { July } 1974}$} \\
\hline & 30 Nov 1974 & $2 \operatorname{Dec} 1974$ & 3 Jan 1975 & 4 Jan 1975 & \\
\hline $\begin{array}{l}\text { Plasma sodium }(\mathrm{mmol} / \mathrm{l}) \\
\text { Plasma potassium }(\mathrm{mmol} / \mathrm{l}) \\
9 \propto \mathrm{F}(\mathrm{mg} / 24 \mathrm{~h}) \\
\text { Salt }(\mathrm{mmol} / 24 \mathrm{~h})\end{array}$ & $\begin{array}{r}124 \\
48 \\
124\end{array}$ & $\frac{5 \cdot 8}{124}$ & $\begin{array}{l}129 \\
4 \cdot 2 \\
0 \cdot 5 \\
77\end{array}$ & $\begin{array}{c}138 \\
4 \cdot 1 \\
0 \cdot 5 \\
77\end{array}$ & $\begin{array}{l}134 \\
\frac{4 \cdot 2}{} \\
\text { Normal diet }\end{array}$ \\
\hline $\begin{array}{l}\text { Steroid excretion }(\mu g / 24 h) \\
\text { Aldosterone metabolites } \\
\text { Tetrahydroaldosterone }\end{array}$ & $<3.5$ & - & - & - & $<3.5$ \\
\hline $\begin{array}{l}\text { Corticosterone metabolites } \\
\text { Tetrahydrocorticosterone } \\
\text { Allo-tetrahydrocorticosterone }\end{array}$ & $\begin{array}{r}89 \\
645\end{array}$ & $\begin{array}{l}127 \\
790\end{array}$ & $\begin{array}{r}72 \\
272\end{array}$ & $\begin{array}{r}30 \\
215\end{array}$ & 172 \\
\hline $\begin{array}{l}\text { 18-OH corticosterone metabolites } \\
\text { 18-OH tetrahydro compound A } \\
18-O H \text { tetrahydrocorticosterone }\end{array}$ & $\begin{array}{l}165 \\
150\end{array}$ & 212 & $\begin{array}{l}48 \\
55\end{array}$ & $\begin{array}{l}49 \\
50\end{array}$ & $\begin{array}{l}650 \\
\text { Not detected }\end{array}$ \\
\hline
\end{tabular}

wasting occurred associated with pyrexia and vomiting (Fig. 1) and $9 \alpha F C$ was increased in a stepwise manner. $\mathrm{Na}$ balance was eventually achieved as indicated by a normal PRA on $77 \mathrm{mmol}$ supplemental $\mathrm{NaCl}$ per day and $0.5 \mathrm{mg} 9 \alpha \mathrm{FC}$ per day. At this time plasma $\mathrm{Na}$ and $\mathrm{K}$ had returned to normal. Blood pressure remained normal on the large dose of mineralocorticoid used, and no further episodes of pyrexia and vomiting occurred. This was followed by a period of catch-up growth.

At the age of 1 year it was possible to reduce the dose of $9 \alpha \mathrm{FC}$ though the child still required the same salt supplementation to maintain sodium balance.

Case 2. A female infant was born at term, birthweight $4.06 \mathrm{~kg}$. She was the first child of healthy unrelated parents. From birth she vomited her feeds frequently and weight gain was poor. She was eventually investigated at the age of 5 months, in view of persistent vomiting and marked growth retardation. She was then small, weight $4.8 \mathrm{~kg}$, height $58 \mathrm{~cm}$. Blood pressure $90 / 60 \mathrm{mmHg}$. External genitalia normal.

Initial investigations showed a normal blood count, sterile urine, and a normal intravenous pyelogram. A barium swallow and meal was also normal. Plasma $\mathrm{Na}$ was $120 \mathrm{mmol} / \mathrm{l}$, and urinary $\mathrm{Na}$ concentration $109 \mathrm{mmol} / \mathrm{l}$.

A salt-wasting state was diagnosed and treated with increased salt supplements (Fig. 2). Na balance was achieved on a daily intake of $70 \mathrm{mmol}$. When the $\mathrm{Na}$ intake was reduced to $12 \mathrm{mmol}$ daily, plasma $\mathrm{Na}$ fell to $125 \mathrm{mmol} / \mathrm{l}$, and at this time PAldo was inappropriately low at 250-278 pmol/1. Further investigations of adrenal function are summarized in Table 1.

Treatment with $9 \alpha \mathrm{FC}(0.025 \mathrm{mg}$ daily) and $\mathrm{NaCl}$ (40 mmol daily) was started. $\mathrm{Na}$ balance and subsequent progress are shown in Fig. 2. $9 \alpha \mathrm{FC}$ was 


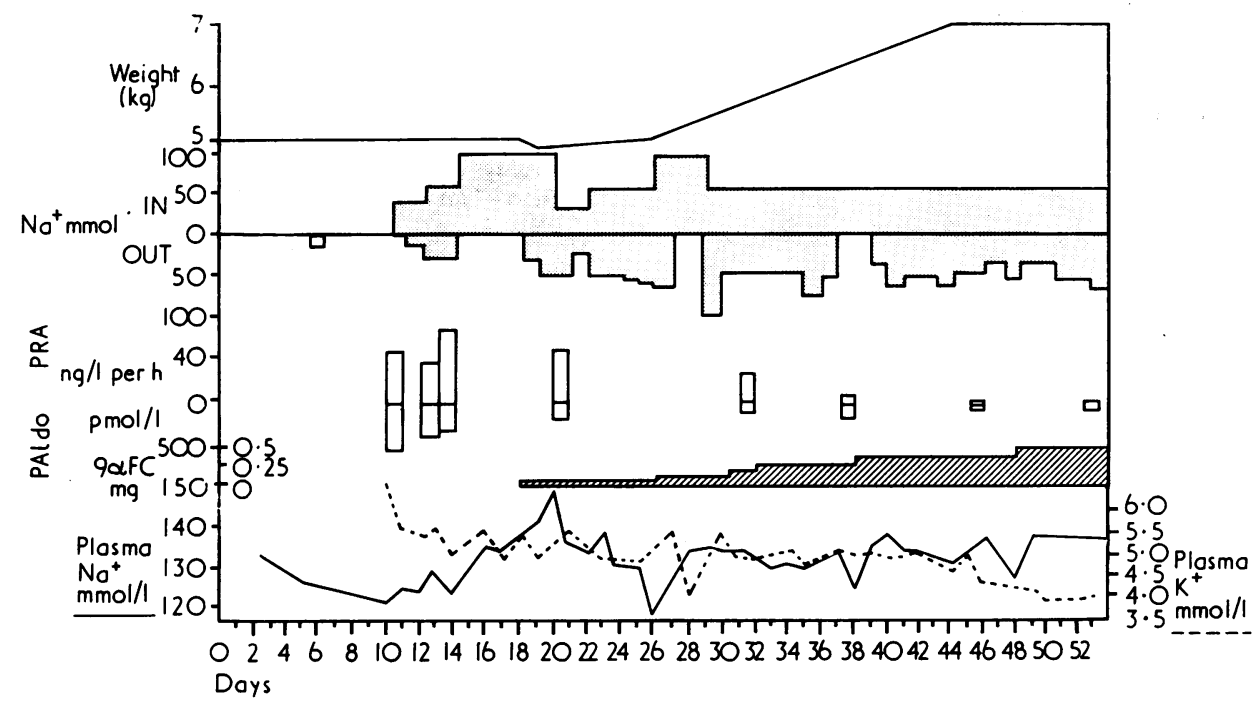

Fig. 1 Case 1. Sodium balance, clinical progress, $P R A / P A l d o$ profiles, and treatment. $P R A=$ plasma renin activity; $P A l d o=$ plasma aldosterone; $9 \alpha F C=9 \alpha$ fludrocortisone .

stopped after 3 weeks and salt balance maintained by dietary $\mathrm{Na}$ supplements of $40 \mathrm{mmol}$ daily. Negative $\mathrm{Na}$ balance ensued and she was restarted on $9 \alpha \mathrm{FC}(0.05 \mathrm{mg}$ daily) and $\mathrm{NaCl}(66 \mathrm{mmol}$ daily) as shown in Fig. 2.

At the age of 23 months she was reinvestigated. She had enjoyed a period of catch-up growth; height and weight were now $81 \mathrm{~cm}$ and $10 \cdot 3 \mathrm{~kg}$ respectively. $\mathrm{Na}$ balance and PRA/PAldo profile studies were undertaken while on treatment with $9 \alpha \mathrm{FC}$ and $\mathrm{NaCl}$, a normal diet, and a low-salt diet.

\section{Laboratory methods}

Plasma and urine electrolytes were measured by flame photometry in a simultaneous 5-channel

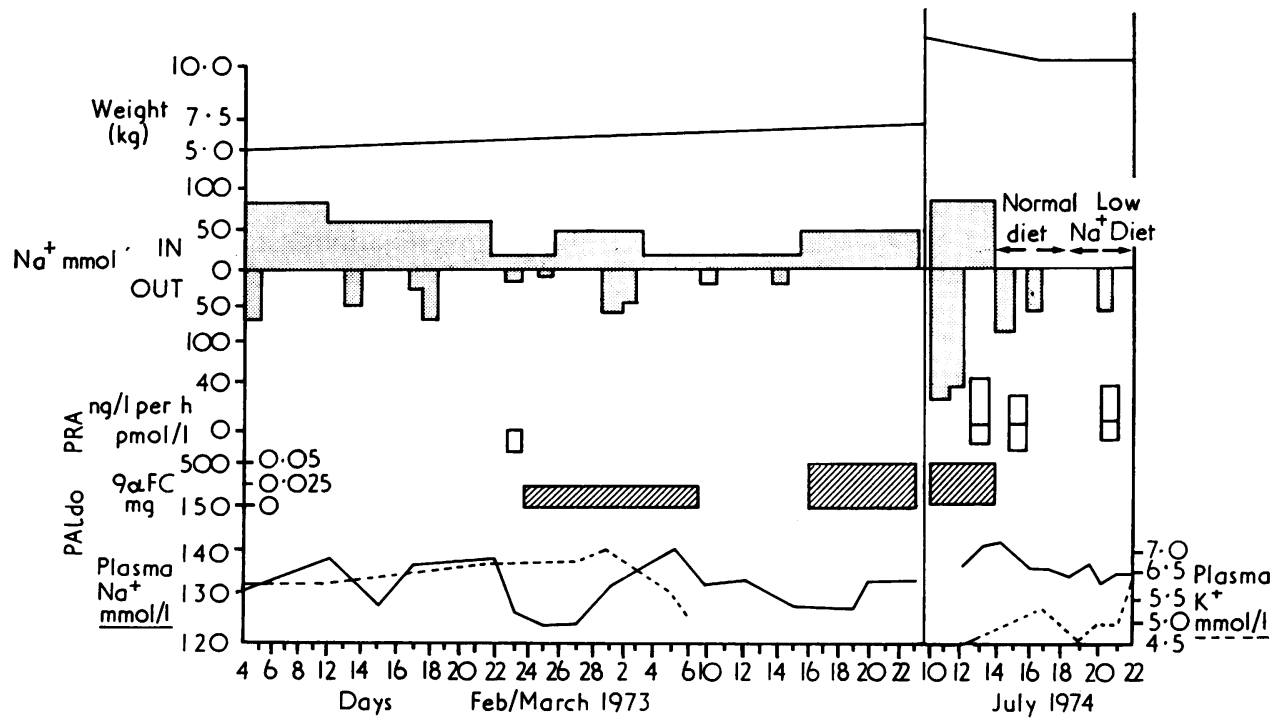

Fig. 2 Case 2. Sodium balance, clinical progress, PRA/PAldo profiles, and treatment. 
Auto-Analyser. Standard methods were used for the estimation of urine 17-hydroxycorticoids (Clayton et al., 1963), 17-oxosteroids (Prout and Snaith, 1958), and the 11-oxygenation index (Clayton et al., 1971). Competitive protein-binding methods were used to determine plasma cortisol (Barnes et al., 1972) and 17-hydroxyprogesterone (Barnes and Atherden, 1972). Plasma ACTH was determined by radioimmunoassay (Rees et al., 1971). PRA was measured by the radioimmunoassay of generated angiotensin I (Dillon, 1975); PAldo was measured by radioimmunoassay after extraction and chromatographic steps (Dillon and Ryness, 1975). Urine aldosterone metabolites and precursors were analysed by gas chromatography-mass spectrometry; the technique is described in detail in a separate communication (Shackleton et al., 1976).

\section{Results}

The PRA/PAldo profiles in both patients in the presence of salt-wasting indicated a defect in the secretion of aldosterone. Congenital adrenal hyperplasia due to 21-hydroxylase deficiency and congenital hypoadrenalism were excluded by the appropriate investigations.

Urinary excretion of aldosterone precursors was abnormal and is given in detail in Table 2. Corticosterone metabolite excretion, particularly allotetrahydrocorticosterone, was grossly raised suggesting a defect in the 18-oxygenation of corticosterone. A defect in 18-dehydrogenation was implied by the increased urinary excretion of 18-hydroxycorticosterone metabolites.

Quantitative data from Case 1 during periods of treatment with salt supplements and when both salt and $9 \alpha \mathrm{FC}$ were administered are summarized in Table 2. Urinary tetrahydroaldosterone secretion correlated with the low PAldo measured at the same time. Excretion of corticosterone and 18hydroxy metabolites was high during the initial salt-wasting period. After administration of $9 \alpha \mathrm{FC}$ and salt (Fig. 1) the excretion of both groups of metabolites fell to 'normal' values (Table 2).

Quantitative data were obtained from Case 2 while on treatment with a normal diet and a low salt diet. Similar results to those of Case 1 were obtained (Table 2). PRA/PAldo profiles during control and treatment periods are given in Table 3 and show the inappropriately low levels of PAldo in relation to PRA at times of negative $\mathrm{Na}$ balance in both patients.

In Case 1, after treatment with salt supplements and $9 \alpha \mathrm{FC}$, PRA fell to normal and the PAldo, though initially normal, decreased further. The
Table 3 PRA/PAldo profiles and treatment data

\begin{tabular}{|c|c|c|c|c|}
\hline \multirow{2}{*}{ Treatment (per 24 h) } & \multicolumn{2}{|l|}{ Case 1} & \multicolumn{2}{|l|}{ Case 2} \\
\hline & $\begin{array}{l}P R A \\
(\text { ng/l per } h)\end{array}$ & $\begin{array}{l}\text { PAldo } \\
(\text { pmol } / \text { l) }\end{array}$ & $\begin{array}{l}P R A \\
(n g / l \text { per } h)\end{array}$ & $\begin{array}{l}\text { PAldo } \\
\text { (pmolll) }\end{array}$ \\
\hline $20 \mathrm{mmol} \mathrm{Na}$ & $\begin{array}{l}48000 \\
40400\end{array}$ & $\begin{array}{l}612 \\
445\end{array}$ & $\begin{array}{l}32552 \\
26720\end{array}$ & $\begin{array}{l}242 \\
486\end{array}$ \\
\hline $77 \mathrm{mmol} \mathrm{Na}$ & 71230 & $\begin{array}{l}445 \\
367\end{array}$ & 20120 & - \\
\hline $\begin{array}{l}124 \mathrm{mmol} \mathrm{Na} \\
0.05 \mathrm{mg} \quad 9 \alpha \mathrm{FC}\end{array}$ & 53660 & 195 & 3948 & 267 \\
\hline $\begin{array}{c}77 \mathrm{mmol} \mathrm{Na} \\
0.2 \mathrm{mg} 9 \alpha \mathrm{Fc}\end{array}$ & 30140 & 139 & - & - \\
\hline $\begin{array}{c}77 \mathrm{mmol} \mathrm{Na} \\
0.3 \mathrm{mg} 9 \alpha \mathrm{FC}\end{array}$ & 3620 & 200 & - & - \\
\hline $\begin{array}{c}77 \mathrm{mmol} \mathrm{Na} \\
0.4 \mathrm{mg} 9 \alpha \mathrm{FC}\end{array}$ & 2040 & 94 & - & - \\
\hline $\begin{array}{l}77 \mathrm{mmol} \mathrm{Na} \\
0.5 \mathrm{mg} \quad 9 \alpha \mathrm{FC}\end{array}$ & 1080 & 94 & - & - \\
\hline
\end{tabular}

level of PRA indicated precisely when $\mathrm{Na}$ balance had been achieved. In Case 2, after treatment with salt and $9 \alpha \mathrm{FC}$, PRA was only marginally raised with a normal PAldo. On normal and low salt diets the PRA was markedly increased with normal PAldo.

\section{Discussion}

Both infants presented initially with persistent vomiting and growth retardation and were ultimately shown to have isolated aldosterone deficiency due to defective 18-dehydrogenation of 18-hydroxycorticosterone. Superficially Case 2 appeared to have only a transient defect.

The existence of transient states of adrenocortical insufficiency in infancy were first suggested by Jaudon in 1946. Russell et al. (1963) described 2 infants with a transient salt-wasting syndrome who responded well to salt-retaining hormones. A temporary biosynthetic defect in aldosterone production was postulated by these authors. In the light of current knowledge of the natural history of 18oxygenation defects, these infants may in reality have suffered from this type of condition.

The conversion of corticosterone to aldosterone is assumed to be a two-step process, a hydroxylation forming 18-hydroxycorticosterone which in turn is dehydrogenated to aldosterone. Greengard et al. (1967) showed that cytochrome P450 is necessary for this step, thus providing evidence that hydroxylation is involved. In the dog, adrenal mitochondria have been shown to require both NADPH and air for the conversion of both corticosterone and 18hydroxycorticosterone to aldosterone suggesting that the reaction is carried out by mixed function oxidases (Marusic et al., 1973).

Assuming that two enzymes are involved, then absence or inactivity of either of them would lead 
to deficient aldosterone synthesis. If the deficiency was of dehydrogenation of 18-hydroxycorticosterone then this would produce high urinary excretion of 18-hydroxytetrahydro compound A (the major metabolite of 18-hydroxycorticosterone), 18hydroxytetrahydrocorticosterone, and metabolites of corticosterone such as allotetrahydrocorticosterone. If the deficiency was of 18-hydroxylation then only raised amounts of corticosterone metabolites would be excreted.

In 1964, Visser and Cost described a family with a urinary salt-wasting disease similar to the infants described here, and found evidence for an 18oxidation defect in the biosynthesis of aldosterone. The disease was later (Degenhart et al., 1966) shown to be due to a defect in 18-hydroxylation. At about the same time Ulick et al. (1964) described a 5-monthold infant with an identical illness and showed that it was due to defective dehydrogenation of 18-hydroxycorticosterone.

Since that time several reports have appeared of defects in 18-oxidation of corticosterone. Of these, two describe defects in 18-hydrogenation (David et al., 1968; Rappaport et al., 1968), and one describes a defect in 18-hydroxylation (Jean et al., 1969). In two further reports it was not possible to define which defect was present (Polonovski et al., 1965; Forsyth (quoted by Cathro), 1967).

In all the reported cases similar correction of the biochemical abnormalities and satisfactory catch-up growth occurred with replacement therapy. However, the amount of mineralocorticoid necessary to suppress production of aldosterone precursors and to control the excessive salt loss in some patients is much greater than that conventionally used in the treatment of salt-losing forms of congenital adrenal hyperplasia or Addison's disease, suggesting perhaps precursor competitive inhibition of the $\mathrm{Na}^{+} \mathrm{K}^{+}$ ATPase transport system of both kidney tubule and gut. The latter is further suggested by the fact that many of the patients during salt-wasting episodes experience diarrhoea and vomiting. In addition, DOCA and aldosterone have been shown in rats to increase the $\mathrm{Na}^{+}$and $\mathrm{K}^{+}$ATPase activity and electrolyte and water transport in both the tubule and colon (Charney et al., 1974, 1975). In experimental hypoadrenal states in rats renal tubular $\mathrm{Na}^{+} \mathrm{K}^{+}$ATPase is profoundly depressed, but after administration of aldosterone, enzymatic activity is completely restored (Schmidt et al., 1975). It is likely that depression of $\mathrm{Na}^{+} \mathrm{K}^{+}$ATPase of both kidney and colon due to deficient secretion of aldosterone is the major factor in the salt-wasting state of these patients.

The course of Case 1 was marked clinically by episodes of salt-wasting associated with mild gastro- intestinal symptoms and pyrexia (Fig. 1). These features were also noted by Visser and Cost (1964) in the 3 patients they described with a defect of 18hydroxylation. Episodes of pyrexia have also been noted in patients with the 21-hydroxylase deficiency form of congenital adrenal hyperplasia, and in some cases ascribed to the pyrogenic effect of steroids such as aetiocholanolone (Cara et al., 1963). The pyrogenic effect of aetiocholanolone was first described by Kappas et al. (1956), who showed that other C-19 and -21 steroids with a $3 \alpha$-hydroxy $-5 \beta$ H configuration had the same pyrogenic effect. Some of the tetrahydro metabolites excreted by Case 1 also have this configuration, and this may explain the episodes of pyrexia in association with episodes of salt-wasting.

In 3 cases reported by David et al. (1968), Jean et al. (1969), and Rappaport et al. (1968) PRA was noted to be raised, but the PRA/PAldo profile was not used to provide an indication of the probable cause of the salt loss. In Case 1, the PRA/PAldo profile, determined early after hospital admission, permitted a speedy diagnosis, and the sequential measurement of PRA also indicated when normal salt balance had been achieved. In Case 2, the PRA/PAldo profile led us to examine the urine sometime after she had been treated empirically with fludrocortisone and salt, but was receiving no treatment for aldosterone precursors, and thus allowed a precise diagnosis. The value of the PRA/PAldo profile in discriminating between renal and adrenal causes of salt loss in childhood has been previously reported (Dillon and Ryness, 1975).

In both patients improvement of the salt-wasting appeared to take place with age, though Case 1 still required salt supplements. The mechanism of agedependent adaptation is not known. After the first year of life the small amount of aldosterone secreted together with mild salt-retaining properties of precursor metabolites may be sufficient, under normal conditions, to maintain salt balance. At about this time, salt craving may become a recognizable stimulus to the child and together with the change to a toddler's diet the daily intake of salt may increase sufficiently to cope with normal life. In addition, maturation of the proximal renal tubule's sodium reabsorption mechanism occurs at about this time. Certainly in the 2 cases described by David et al. (1968) the administration of salt seemed to be a crucial factor.

The initial presenting features are often subtle and in many cases the disease may appear to be transient. In a few patients studied longitudinally (Rappaport et al., 1968), though there was improvement of salt-wasting and the defect appeared to be transient superficially, the biosynthetic defect persisted. This 
apparent temporary nature of the condition may mask its true incidence and the defect may be commoner than might be suspected from the existing reports.

During salt-wasting episodes either at initial presentation or later during intercurrent infections, relatively high doses of salt and mineralocorticoid are necessary to achieve positive $\mathrm{Na}$ balance. Once suppression of precursors has been achieved positive $\mathrm{Na}$ balance can be obtained with more conventional doses of mineralocorticoid and salt. Growth rate however may remain abnormally low unless positive $\mathrm{Na}$ balance is assured either by treatment or by a self-selected diet by the patient.

We thank Professor O. H. Wolff and Dr. R. H. R. White for permission to publish their cases; Mrs. Jennifer Ryness for undertaking the plasma aldosterone assay; Dr. Leslie Rees for the plasma ACTH assay; and Mrs. Vanita Shah for expert technical assistance. M.J.D. was supported by the Buttle Trust.

\section{References}

Barnes, N. D., and Atherden, S. M. (1972). Diagnosis of congenital adrenal hyperplasia by measurement of 17 hydroxyprogesterone. Archives of Disease in Childhood, 47, 62-65.

Barnes, N. D., Joseph, J. M., Atherden, S. M., and Clayton, B. E. (1972). Functional tests of adrenal axis in children with measurement of plasma cortisol by competitive protein binding. Archives of Disease in Childhood, 47, 66-73.

Cara, J., Beas, F., Spach, C., and Gardner, L. I. (1963). Increased urinary and plasma etiocholanolone and related steroids in a boy with virilizing adrenal hyperplasia and periodic fever. Journal of Pediatrics, 62, 521-530.

Charney, A. N., Silva, P., Besarab, A., and Epstein, F. H. (1974). Separate effects of aldosterone, DOCA, and methylprednisolone on renal sodium and potassium ATPase. American Journal of Physiology, 227, 345-350.

Charney, A. N., Kinsey, M. D., Myers, L., Giannella, R. A., and Gots, R. E. (1975). Sodium and potassium activated ATPase and intestinal electrolyte transport. Journal of Clinical Investigation, 56, 653-660.

Clayton, B. E., Edwards, R. W. H., and Renwick, A. G. C. (1963). Adrenal function in children. Archives of Disease in Childhood, 38, 49-53.

Clayton, B. E., Edwards, R. W. H., and Makin, H. L. (1971). Congenital adrenal hyperplasia and other conditions associated with a raised urinary steroid 11-oxygenation index. Journal of Endocrinology, 50, 251-265.

David, R., Golan, S., and Drucker, W. (1968). Familial aldosterone deficiency: enzyme defect, diagnosis and clinical course. Pediatrics, 41, 403-412.

Degenhart, H. J., Frankena, L., Visser, H. K. A., Cost, W. S., and van Seters, A. P. (1966). Further investigation of a new hereditary defect in the biosynthesis of aldosterone. Evidence for a defect in 18-hydroxylation of corticosterone. Acta Physiologica et Pharmacologica Neerlandica, 14, 88-89.
Dillon, M. J. (1975). Measurement of plasma renin activity by semi-micro radioimmunoassay of generated angiotensin I. Journal of Clinical Pathology, 28, 625-630.

Dillon, M. J., and Ryness, J. M. (1975). Plasma renin activity and aldosterone concentration in children. British Medical Journal, 4, 316-319.

Forsyth, C. (1967). Personal communication quoted by Cathro, D. M. Adrenal cortex and medulla. Paediatric Endocrinology, p. 276. Ed. by D. Hubble. Blackwell, Oxford.

Greengard, P., Psychoyos, S., Tallan, H. H., Cooper, D. Y., Rosenthal, O., and Estabrook, R. W. (1967). Aldosterone synthesis by adrenal mitochondria. III. Participation of cytochrome P-450. Archives of Biochemistry and Biophysiology, 121, 298-303.

Hamilton, W., McCandless, A. E., Ireland, J. T., and Gray, C. E. (1976). Hypoaldosteronism in three sibs due to 18-dehydrogenase deficiency. Archives of Disease in Childhood, 51, 576-583.

Jaudon, J. C. (1946). Hypofunction of the adrenals in early life. Journal of Pediatrics, 29, 696-710.

Jean, R., Legrand, J.-C., Meylan, F., Rieu, D., and Astruc, J. (1969). Hypoaldostéronisme primaire par anomalie probable de la 18-hydroxylation. Archives Françaises de Pédiatrie, 26, 769-778.

Kappas, A., Hellman, L., Fukushima, D. K., and Gallagher, T. F. (1956). The pyrogenic effects of etiocholanolone (3 $\alpha$-hydroxyetiocholanolone-17-one). Journal of Clinical Endocrinology and Metabolism, 16, 948.

Marusic, E. T., White, A., and Aedo, A. R. (1973). Oxidative reactions in the formation of an aldehyde group in the biosynthesis of aldosterone. Archives of Biochemistry and Biophysics, 157, 320-321.

Polonovski, C., Zittoun, R., and Mary, F. (1965). Hypocorticisme global, hypoaldostéronisme et pseudohypoaldostéronisme du nourrisson. Archives Françaises de Pédiatrie, 22, 1061-1086.

Prout, M., and Snaith, A. H. (1958). Urinary excretion of 17-ketosteroids in children. Archives of Disease in Childhood, 33, 301-304.

Rappaport, R., Dray, F., Legrand, J. C., and Royer, P. (1968). Hypoaldostéronisme congénital familial par défaut de la 18-OH-déhydrogénase. Pediatric Research, 2, 456-463.

Rees, L. H., Cook, D. M., Kendall, J. W., Allen, C. F., Kramer, R. M., Ratcliffe, J. G., and Knight, R. A. (1971). Radioimmunoassay for rat plasma ACTH. Endocrinology, 89, 254-261.

Russell, A., Levin, B., Sinclair, L., and Oberholzer, V. G. (1963). A reversible salt-wasting syndrome of the newborn and infant. Archives of Disease in Childhood, 38, 313-325.

Schmidt, U., Schmid, J., Schmid, H., and Dubach, U. C. (1975). Sodium- and potassium-activated ATPase. A possible target of aldosterone. Journal of Clinical Investigation, 55, 655-660.

Shackleton, C. H. L., Honour, J. W., Dillon, M., and Milla, P. (1976). Multicomponent gas chromatographic analysis of urinary steroids excreted by an infant with a defect in aldosterone biosynthesis. Acta Endocrinologica, 81, 762-773.

Ulick, S., Gautier, E., Vetter, K. K., Markello, J. R., Yaffe, S., and Lowe, C. U. (1964). An aldosterone biosynthetic defect in a salt-losing disorder. Journal of Clinical Endocrinology and Metabolism, 24, 669-672.

Visser, H. K. A., and Cost, W. S. (1964). A new hereditary defect in the biosynthesis of aldosterone: urinary $\mathrm{C}_{21^{-}}$ corticosteroid pattern in three related patients with a salt-losing syndrome suggesting an 18-oxidation defect. Acta Endocrinologica, 47, 589-612. 
Correspondence to Dr. P. J. Milla, Institute of Child Health, 30 Guilford Street, London WC1N $1 \mathrm{EH}$.

\section{Addendum}

The patients we have described certainly suffer from the same condition as the family recently described by Hamilton et al. (1976). This latter family emphasizes that though salt-wasting may improve, the biosynthetic defect persists, and growth requires adequate sodium homoeostasis to be maintained.
If the diagnostic techniques now available had been established at the time of initial presentation of the older sib an earlier diagnosis undoubtedly would have been made. PRA/PAldo profile coupled with urinary gas liquid chromatography/mass spectrometry is a very powerful tool for the rapid evaluation of the less common salt-losing disorders of childhood. The technique of GLC/mass spectrometry is extremely useful in situations where poorly characterized metabolites may be encountered for which reference compounds are not available. The technique also enables a complete profile of the metabolites excreted to be obtained at one examination.

The following articles will appear in future issues of this journal:

Quality of survival after severe birth asphyxia. Alison J. Thomson, Margaret Searle, and G. Russell.

Elimination of pethidine and bupivacaine in the newborn. L. V. Cooper, G. W. Stephen, and P. J. A. Aggett. Crohn's disease in childhood. D. P. O'Donoghue and A. M. Dawson.

Determination of glomerular function in advanced renal failure. F. Manz, H. Alatas, W. Kochen, P. Lutz, $W$. Rebien, and $K$. Schärer.

Hereditary coproporphyria and epilepsy. A. B. Houston, M. J. Brodie, M. R. Moore, G. G. Thompson, and J. B. P. Stephenson.

Psychiatric disturbance, urgency, and bacteriuria in children with day and night wetting. I. Berg, Dorothy Fielding, and R. Meadow.

Failure to thrive at the breast: an old problem revisited. T. J. Evans and D. P. Davies.

Cystinotic rickets treated with vitamin D metabolites. P. Etches, D Pickering, and R. Smith. 